\title{
Effect of denervation on the red and white fibres of the pectoralis muscle of the pigeon ${ }^{1}$
}

\author{
K. M. CHERIAN, F. D. BOKDAWALA, N. V. VALLYATHAN, AND \\ J. C. GEORGE \\ From the Division of Animal Physiology and Histochemistry, Department of Zoology, \\ M.S. University of Baroda, Baroda, India
}

Recent studies on the biochemical properties of the red and white fibres of the pigeon breast muscle have shown that these cell types are not mere morphological entities but differ fundamentally in structure and metabolism (George and Naik, 1959; George and Talesara, 1961, 1962a, 1962b). The red fibres have been found to be adapted for an aerobic metabolism capable of metabolizing fat as their energy fuel and the white fibres for an anaerobic metabolism utilizing glycogen. In such a mixed muscle composed of highly specialized cell types, the changes brought about by induced atrophy of the muscle, such as immobilization or denervation, should be of considerable interest for a basic understanding of the processes involved in muscular atrophy.

Histological and histochemical studies (George and Naik, 1959; Vallyathan, Cherian, and George, 1964; Cherian, Vallyathan, and George, 1965) on the breast muscle of the pigeon subjected to disuse atrophy have shown that the white fibres are more susceptible to atrophy than the red ones. The red fibres become adapted to an increased glycolytic metabolism by acquiring more glycogen and phosphorylase and simultaneously losing succinic dehydrogenase activity. The white fibres, on the other hand, showed increased oxidative metabolism and lowered glycolytic metabolism (Vallyathan et al., 1964; Cherian et al., 1965). Biochemical investigations on the lipid levels and lipase activity in the muscle and blood (George and Vallyathan, 1962) and the capacity of the muscle for fatty acid oxidation and R.Q. studies (Vallyathan, Cherian, and George, 1965) revealed a shift in the overall metabolism of the muscle from aerobic to anaerobic with increased lipogenesis.

However, the above studies were carried out on pigeons with immobilized wings and so slight muscular movements were possible, which reduced

${ }^{1}$ This work was supported by a personal grant to Dr. J. C. George from the Muscular Dystrophy Associations of America. the extent of atrophy. It was therefore thought necessary to conduct the present histochemical investigation on the localization of glycogen, fat, phosphorylase, succinic dehydrogenase (SDH), pentose cycle dehydrogenases, $\beta$-hydroxybutyric dehydrogenase, acid and alkaline phosphatases, lipase, and esterase on the denervated breast muscle of the pigeon.

\section{MATERIAL AND METHODS}

Twenty fully grown adult healthy pigeons of either sex weighing from 300 to $320 \mathrm{~g}$. were used. Sixteen of these were used for the denervation studies and four as controls. The pigeons were anaesthetized by covering the head with a mask containing cotton wool soaked in ether. After one minute of ether administration, an incision was made at the base of the neck, and the brachial plexus of one side was transected by the removal of about $1 \mathrm{~cm}$. of the plexus at the level of the clavicle. The denervated pigeons were then left with the others, which were used as controls. They were fed on a normal diet of grain. At the end of the scheduled experimental period, the bird was decapitated and pieces of the breast muscle were immediately excised and blotted to remove the blood. After collecting the muscle samples, the animals were examined to record the state of the transected nerve. In none of the cases was there any sign of reinnervation of the muscle, since the nerve was excised after full extension of the wing thus enabling complete separation of the cut ends. The isolated muscle pieces were frozen by plunging them into liquid air for about two minutes. These were then transferred to a cryostat at $-20^{\circ} \mathrm{C}$. and stored in protective containers till the time of use. Sections of $6 \mu$ thickness were cut, fixed to coverslips, and then finger thawed and air dried for three minutes for the following histochemical observations.

GLYCOGEN For the demonstration of glycogen, sections were fixed in Rossman's fluid at $4^{\circ} \mathrm{C}$. for 10 minutes. After fixation, they were passed through ethanol grades and stained, employing the P.A.S. technique (Pearse, 1960). Sections treated in saliva for 30 minutes at $37^{\circ} \mathrm{C}$. served as controls. 
FAT Sections were fixed in Baker's calcium formol for one hour, washed in distilled water, and stained with Sudan black B in $70 \%$ ethanol.

PHOSPHORYLASE Histochemical demonstration of phosphorylase activity was carried out according to the method of Eränkö and Palkama (1961) using glucose-1-phosphate as the substrate. The sections were incubated at $30^{\circ} \mathrm{C}$. for 15 minutes, rinsed in $40 \%$ alcohol, and stained with Gram's iodine for one minute. Unincubated sections and sections incubated in the medium without substrate formed the controls.

PENTOSE CYCLE DEHYDROGENASES Glucose-6-phosphate dehydrogenase and 6-phosphogluconate dehydrogenase were demonstrated according to the procedures of Pearse (1960) using nitro BT as the hydrogen acceptor.

SUCCINIC DEHYDROGENASE (SDH) Succinic dehydrogenase activity was demonstrated according to the modified method of George and Talesara (1961), using nitro BT as the hydrogen acceptor.

$\beta$-HYDROXYBUTYRIC DEHYDROGENASE This enzyme was localized by the procedure of Pearse (1960) making use of nitro BT.

LIPASE Localization of lipase activity was carried out by the method of Bokdawala and George (1964) using Tween 85 as substrate and alizarin red $\mathbf{S}$ for staining the calcium soap formed.

TWEEN 20 ESTERASE This enzyme was studied by the method of Gomori (1952) using Tween 20 as the substrate.

ACID AND ALKALINE PHOSPHATASES For acid and alkaline phosphatases the procedure of Gomori (1952) was employed with sodium $\beta$-glycerophosphate as the substrate at $p \mathrm{H} 5.2$ and 9.2 respectively.

\section{RESULTS}

The control experiments were all conducted on the normal pigeon breast muscle. It was found that in the denervated pigeon, besides atrophy of the denervated muscle, the contralateral muscle also underwent certain atrophic changes, which could perhaps be attributed to the inactivity of the muscle brought about by the loss of synchronous flapping of the wings as a result of denervation. As a criterion for atrophy, the weight loss and the fibre diameter of the muscle were studied. It was observed that during the experimental intervals of the longitudinal study, there was a progressive loss of weight which was found to be due to the loss of muscle mass. In the control animals, the weight of the pectoralis muscle is nearly $8 \%$ of the total body weight while in the experimental animals the weight noted after 30 days of denervation was $4.2 \%$ of the total body weight. The fibre diameter was also considerably reduced in both types of fibres after 30 days of denervation (Table I).

\section{TABLE I}

DIAMETER OF THE RED AND WHITE FIBRES IN NORMAL AND DENERVATED PECTORALIS MUSCLE OF THE PIGEON

\begin{tabular}{ccc}
$\begin{array}{l}\text { No. of Days } \\
\text { of Denervation }\end{array}$ & $\begin{array}{c}\text { Diameter of } \\
\text { Red Fibres } \\
(\mu)\end{array}$ & $\begin{array}{c}\text { Diameter of } \\
\text { White Fibres } \\
(\mu)\end{array}$ \\
\hline 7 & 31 & 70 \\
14 & 25 & 53 \\
21 & 26 & 50 \\
30 & 22 & 36 \\
Normal control & 35 & 74
\end{tabular}

The data presented are the average fibre diameters of samples of muscles taken from four animals in each case. Sections fixed in calcium formol were used for measuring the fibre diameter.

NORMAL MUSCLE In the normal pigeon breast $\vec{\rho}$ muscle, the metabolites and enzymes studied show a definite pattern in their localization. The white $\frac{5}{0}$ fibres, which are glycogen-loaded, show a higher phosphorylase activity than the red fibres which are fat-loaded. All the dehydrogenases are very active io i the red fibres and less so in the white fibres. Lipas 8 is chiefly localized in the mitochondria of the ref fibres whereas Tween 20 esterase is restricted to the cytoplasm of both the types of fibres. The activity for $\square$ acid and alkaline phosphatases was found to be very low.

In the normal pigeon breast muscle section $\overrightarrow{0}$ satisfactory histochemical demonstration of the enzymes under investigation is achieved within a specific time of incubation: phosphorylase is demonstrated in $10 \mathrm{~min}$.; pentose cycle dehydrogenases in $1.30 \mathrm{hr}$; succinic dehydrogenase in $10 \mathrm{~min}$.; $\beta$-hydroxybutyric dehydrogenase in one $\mathrm{hr}$.; Tween 20 esterase in eight hr.; lipase in $20 \mathrm{hr}$. However, for a proper comparison, the control and experimental sections were incubated and stained together for the same length of time under identical conditions. The control experiments carried out on the normal muscle, therefore, depict a picture of intensive activity for some of the enzymes and low activity for others (Figs. 1-4). In the case of some enzymes the experimental sections required longer incubation whereas in others a shorter period was necessary for a satisfactory demonstration of enzymatic activity.

DENERVATED MUSCle The changes in the muscle caused by denervation were progressive with the length of atrophy. There was an enormous prolifera- tion of connective tissue and a consequent reduction in the muscle mass. The majority of muscle fibres 

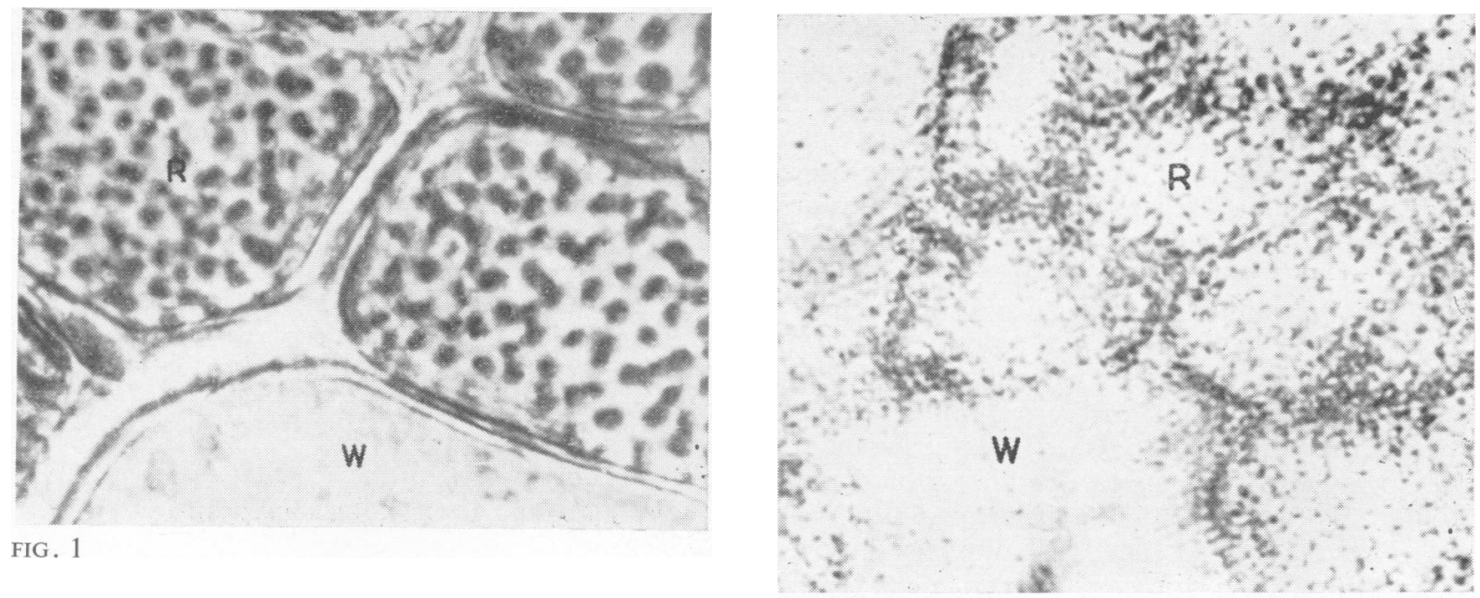

FIG. 3
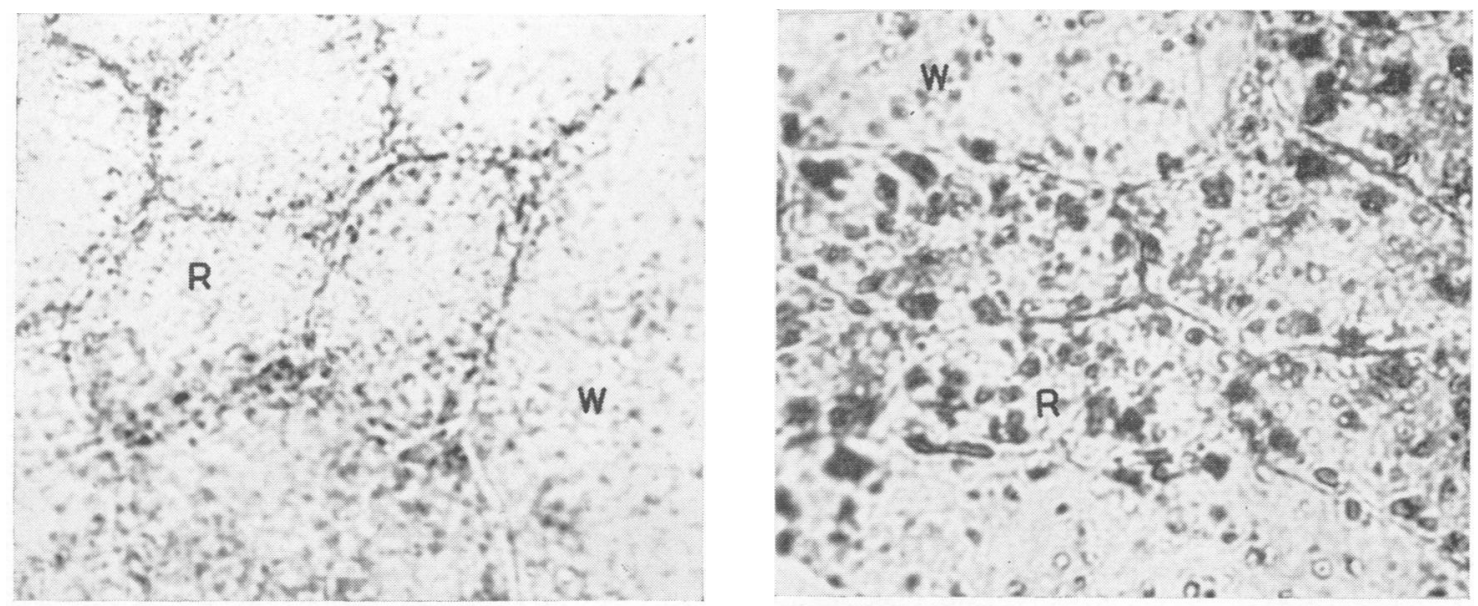

FIG. 2

FIG. 4

FIG. 1. Photomicrograph of the transverse section of pectoralis muscle of a normal pigeon stained with Sudan black $B$ for the demonstration of fat. The red fibres $(R)$ are more sudanophilic than the white fibres $(W)$ and their mitochondria are deeply stained. $\times 1,200$.

FIG. 2. Photomicrograph of a transverse section of the normal pectoralis muscle showing the histochemical localization of glucose-6-phosphate dehydrogenase activity. Note the low enzymatic activity due to insufficient incubation (45 min.). $\times$ 1,010. Compare with Figure 9 .

FIG. 3. Photomicrograph of a transverse section of the normal pectoralis muscle showing the distribution pattern of $\beta$-hydroxybutyric dehydrogenase. A relatively low activity of this enzyme is seen in the red $(R)$ as well as white $(W)$ fibres, as a result of a short period of incubation (45 min.). $\times 1,010$. Compare with Figure 11.

FIG. 4. Photomicrograph of a transverse section of the normal pectoralis muscle treated to show the localization pattern of Tween 20 esterase. Enzyme activity seems to be mainly localized in the form of dense precipitates in the cytoplasm of both types of fibres. The red fibres $(R)$ show numerous precipitates which are larger than those of the white fibres $(W)$. The formation of large precipitates is attributed to the longer duration of incubation (24 hr.) carried out in accordance with the requirements of the sample sections (Fig. 14). $\times 1,010$. 
were found to be degenerated after 30 days of atrophy. It was also noted that many of the red as well as white fibres were filled with fat during the early days. The changes in glycogen content and phosphorylase activity varied slightly, as observed in disuse atrophy. Earlier stages of atrophy appeared to bring about visible changes in the sarcoplasmic reticulum and mitochondria which were observed to be swollen and to lose their usual structure.

GLYCOGEN Seven days after denervation there was an increase of glycogen in the red fibres and a decrease in the white fibres. After 14 days, some of the red fibres were also found to be devoid of glycogen (Fig. 5). By the 21st and 30th days, a majority of the red fibres had lost practically all their glycogen. Connective tissue, however, showed a gradual increase in glycogen content during this period.

FAT During atrophy both types of fibre became less sudanophilic when compared with the normal fibres. A few red as well as white fibres, but more of the former, were found to be loaded with considerably more fat (Fig. 17). There was also an increase in intramuscular fat which was more towards the region of the blood vessels (Figs. 7 and 8 ).

PHOSPHORYLASE In the initial period after denervation, there was an increase of phosphorylase in most of the red fibres while in some others the enzyme activity was absent (Fig. 6). After seven days it was observed that the degenerating white fibres had lost their enzyme activity. The presence of enzyme activity after $\mathbf{3 0}$ days was seen only in a few of the red and white fibres but the intensity of the reaction was considerably less. The red blood cells and arterial walls also showed enzymic activity.

PENTOSE CYCLE DEHYDROGENASES Both the dehydrogenases of the pentose cycle tested were highly active during atrophy. After seven days there was a uniform increase in activity in the red fibres, but during the later days of atrophy the white fibres also showed an increase in the enzyme activity (Fig. 9). Among the red fibres there were a few which stained very dark for both the enzymes after seven days. It was also observed that the degenerating white fibres possessed very high concentrations of the enzymes (Fig. 10). The connective tissue mass and the arterial walls also showed a positive reaction for both the enzymes.

$\beta$-HYDROXYBUTYRIC DEHYDROGENASE The pattern of this enzyme activity was very similar to that of the pentose cycle dehydrogenases (Fig. 11). There was an overall increase in the enzyme activity throughout the experimental period. In the degenerating fibres $\bar{Z}$ a very sharp increase was noted which was much $\stackrel{\mathbb{D}}{=}$ higher than that observed for the pentose cycle enzymes. The sarcolemmal regions of the fibres were deeply stained and the connective tissue and blood vessels also showed a faint positive reaction. SUCCINIC DEHYDROGENASE (SDH) The activity of this enzyme during atrophy decreased considerably $\vec{z}$ in the muscle. After 14 days the red fibres presented a mosaic appearance with regard to the level of the $\stackrel{\vec{F}}{+}$ enzyme activity. The white fibres generally showed an increase in enzyme activity. The diversity in the $\frac{\bar{\sigma}}{\bar{N}}$ enzyme activity among the red fibres persisted even $\frac{\bar{\sigma}}{\widehat{D}}$ after 30 days of denervation (Fig. 12).

LIPASE Throughout the experimental period there was a decrease in lipase activity (Fig. 13).

TWEEN 20 ESTERASE Despite the slight increase in $\vec{\sigma}$ activity within the first seven days, there was a reduction in the enzyme level in the later periods (Fig. 14).

ACID PHOSPHATASE On the seventh day the activify of this enzyme was very low. A higher enzynaf 8 activity was noticed in the red fibres than in the whife의 ones after 14 and 21 days of denervation. During thas period, connective tissue and degenerating fibres $\square$ showed intensive activity (Fig. 18). After 30 days, 0 only a negligible amount of the enzyme activi⿺ of could be detected in the connective tissue (Fig. 15). 흑. ALKALINE PHOSPHATASE This enzyme was observed to be present in low concentrations during atrophy of the muscle. However, the red fibres showed a higher level of enzyme activity than the white ones (Fig. 16). Connective tissue showed a negative reaction throughout the experimental period.

\section{DISCUSSION}

The present observations made on the denervated breast muscle of the pigeon revealed significant differences in the metabolism of the two types of fibres as compared to those in the control animals. These changes could be mainly attributed to the degree of susceptibility to atrophy of the two types of fibre. Earlier studies reported by Vallyathan et al. $\stackrel{\varrho}{2}$ (1964) have shown that during immobilization atrophy of the breast muscles in pigeons the white $\frac{\text { ? }}{3}$ fibres showed degenerative changes more rapidly $>$ than the red ones. They also showed that there was a shift in the metabolic pattern of the red fibres by acquiring more glycogen and phosphorylase. Similar results with regard to the pattern of changes in $N$ glycogen and phosphorylase were also obtained in 


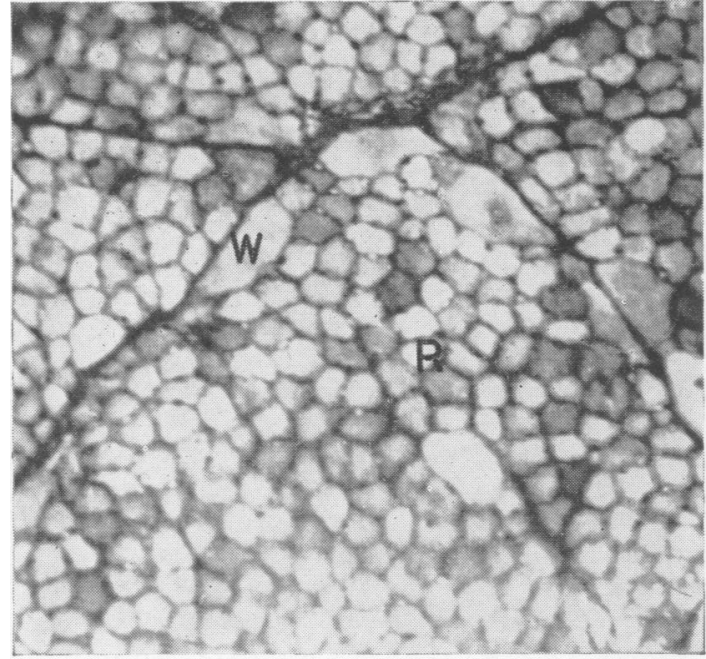

FIG. 5

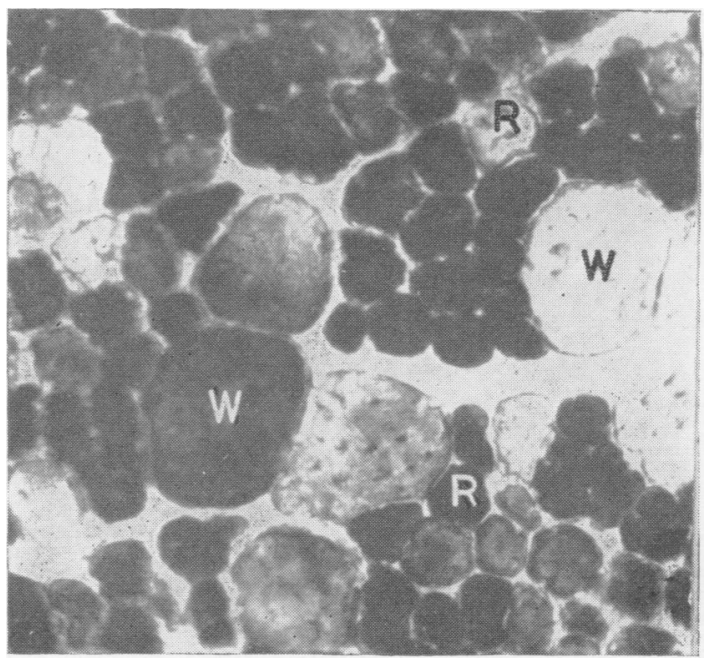

FIG. 6

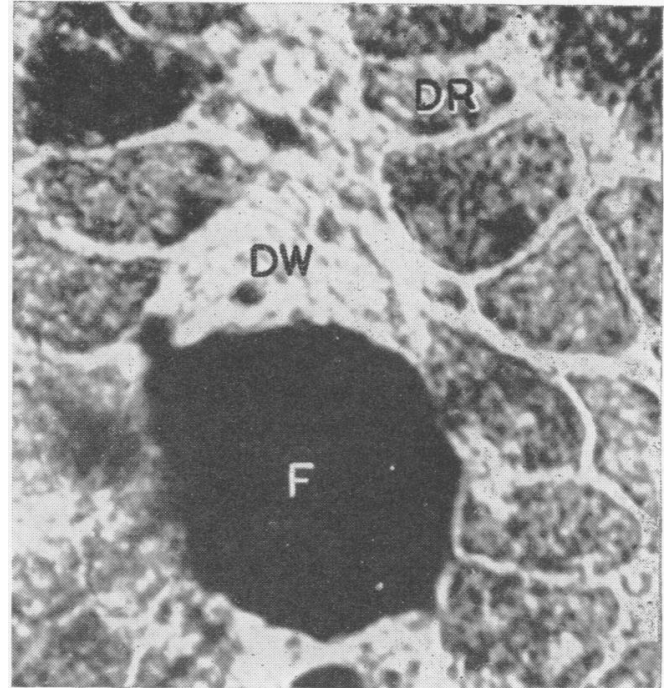

FIG. 7

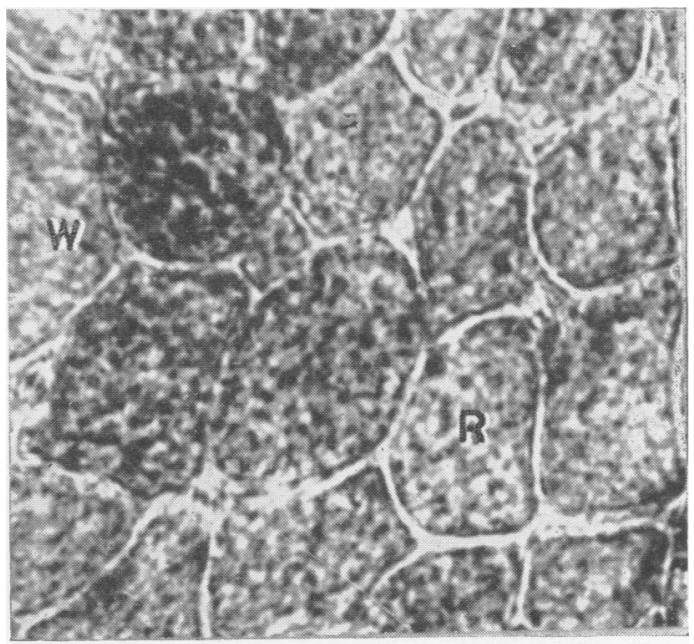

FIG. 8

FIG. 5. Photomicrograph of a P.A.S.-stained transverse section of denervated pectoralis muscle 14 days after denervation. Majority of the white fibres $(W)$ and some of the red ones $(R)$ are P.A.S.-negative. Reduction in the fibre diameter is evident. $\times 400$.

FIG. 6. Photomicrograph of a transverse section of the denervated pectoralis muscle seven days after denervation treated for phosphorylase activity. Some of the white fibres. (W) are found to be devoid of the enzyme activity. Majority of the red fibres $(R)$ show an intense positive reaction. Incubation time, 15 min., $\times 260$.

FIG. 7. Photomicrograph of a transverse section of pectoralis muscle 21 days after denervation, showing the deposition of fat in the inter-and intra-fibrillar spaces. Note the densely fat-loaded red fibre at the top left-hand corner and the nonsudanophilic degenerating white fibre $(D W)$ seen above the large deposit of fat $(F)$ present between the fibres. Note the partially degenerated red fibre $(D R) . \times 1,010$.

FIG. 8. Photomicrograph of a transverse section of pectoralis muscle 30 days after denervation stained for fat showing a less affected area. $\times 1,010$. 


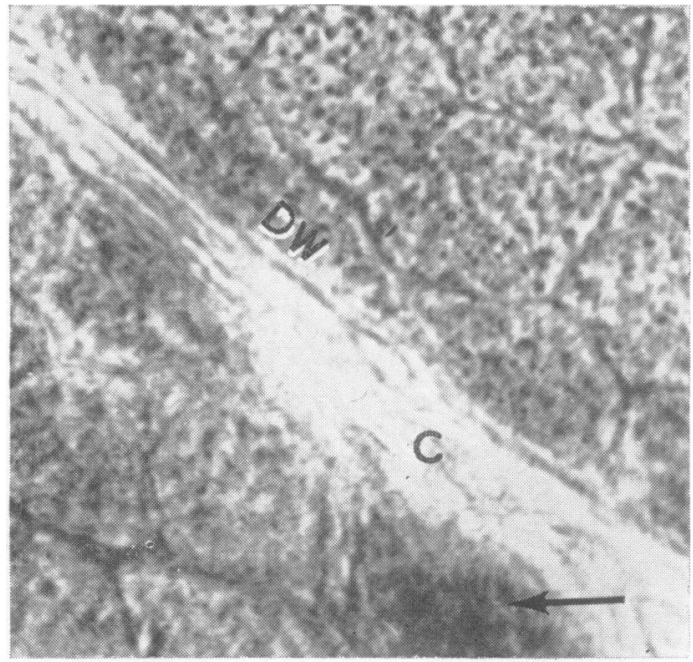

FIG. 9

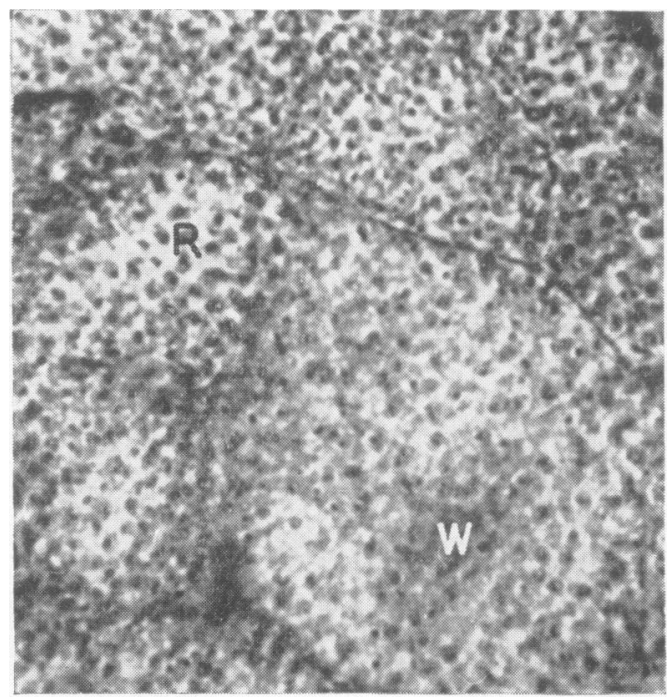

FIG. 11

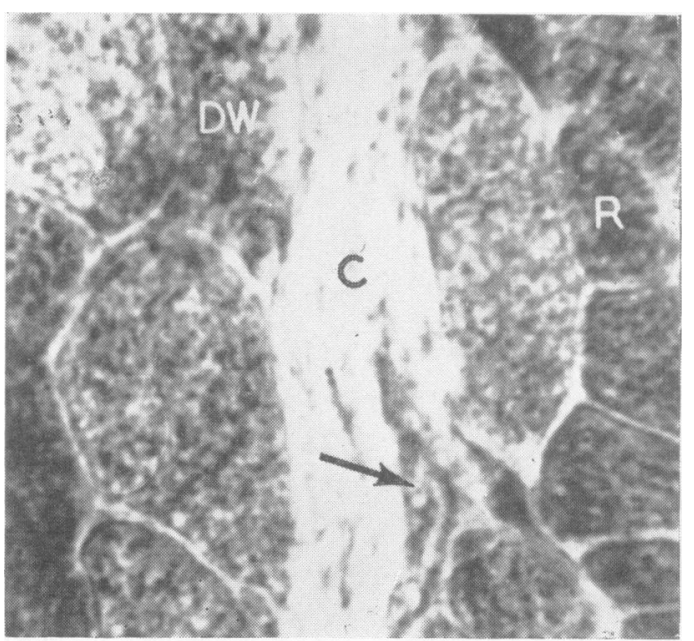

FIG. 10

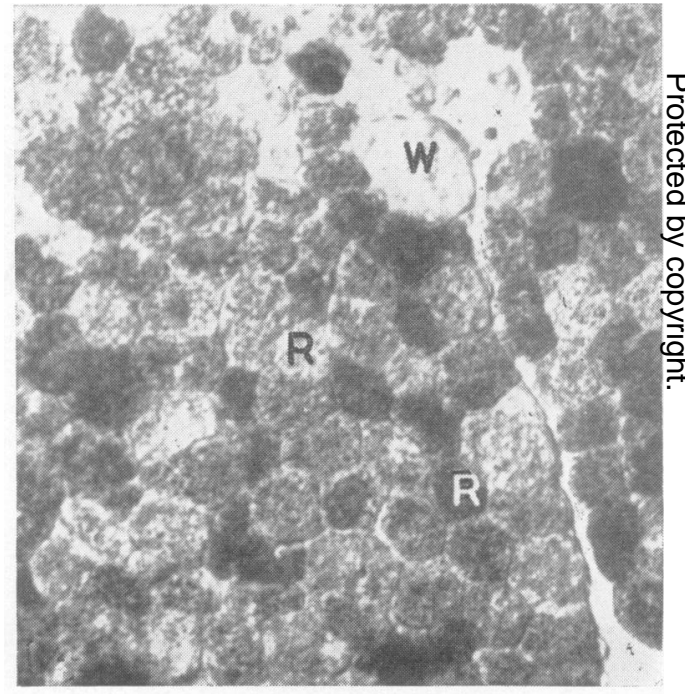

FIG. 12

FIG. 9. Photomicrograph of a transverse section of pectoralis muscle 30 days after denervation showing the histochemical distribution of glucose-6-phosphate dehydrogenase activity. The white fibre undergoing degeneration (indicated by the arrow) shows high enzyme activity. The connective tissue $(C)$ also shows a positive reaction. Note the higher enzyme activity in both the types of fibre. Compare with Fig. 2. Incubation time, 45 min., $\times 1,010$.

FIG. 10. Photomicrograph of a transverse section of pectoralis muscle 30 days after denervation showing the localization $\frac{0}{3}$ pattern of 6-phosphogluconic dehydrogenase activity. Note the fragments of a white fibre (indicated by the arrow). Some of the red fibres are strongly reactive. Connective tissue $(C)$ also shows positive reaction. Incubation time, 45 min., $\times 1,010$. 윽

FIG. 11. Photomicrograph of a transverse section of pectoralis muscle seven days after denervation showing an $\frac{D}{O}$ overall increase of $\beta$-hydroxybutyric dehydrogenase activity in both the types of fibres as compared with the normal (Fig.3). ․ㅡ․ The reduction in diameter of the fibres is not yet discernible. Incubation time, 45 min., $\times 1,010$.

FIG. 12. Photomicrograph of a transverse section of pectoralis muscle 30 days after denervation showing the variation in the level of succinic dehydrogenase activity among the narrow fibres. Some of the red fibres are darkly stained, some 0 show moderate activity while others hardly any activity at all. Incubation time, one hour, $\times 260$. 


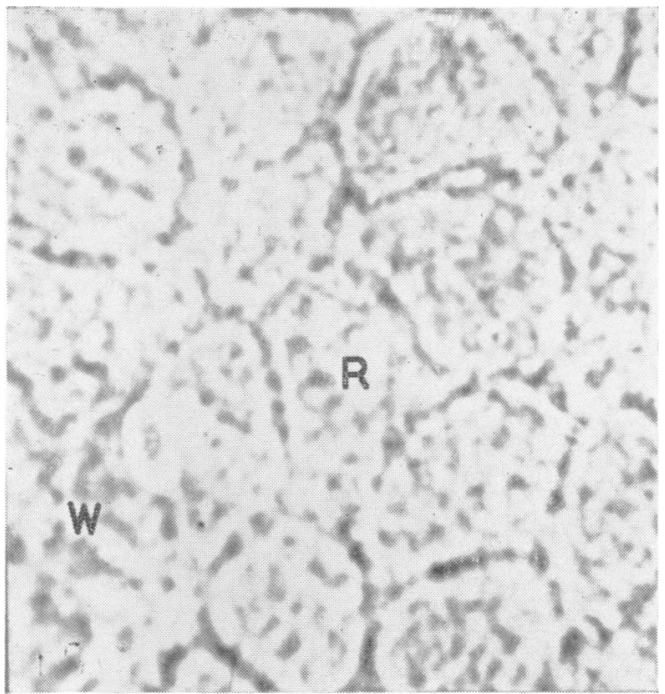

FIG. 13

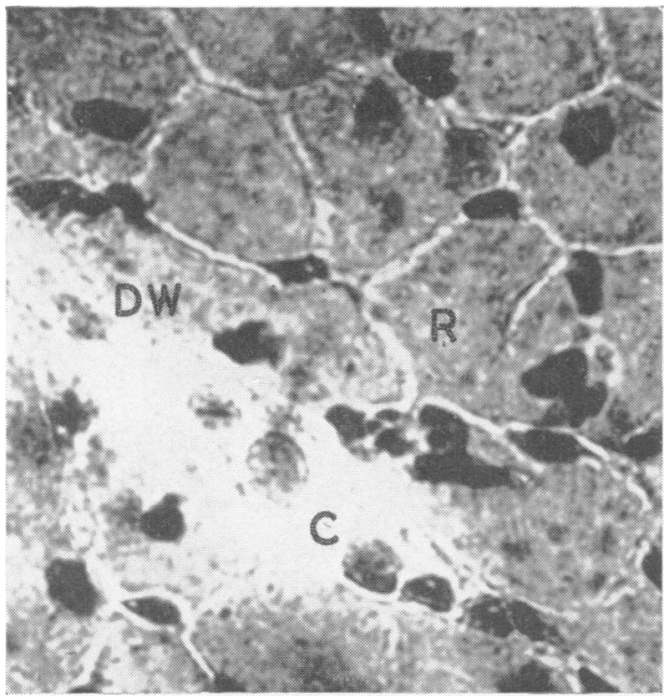

FIG. 15

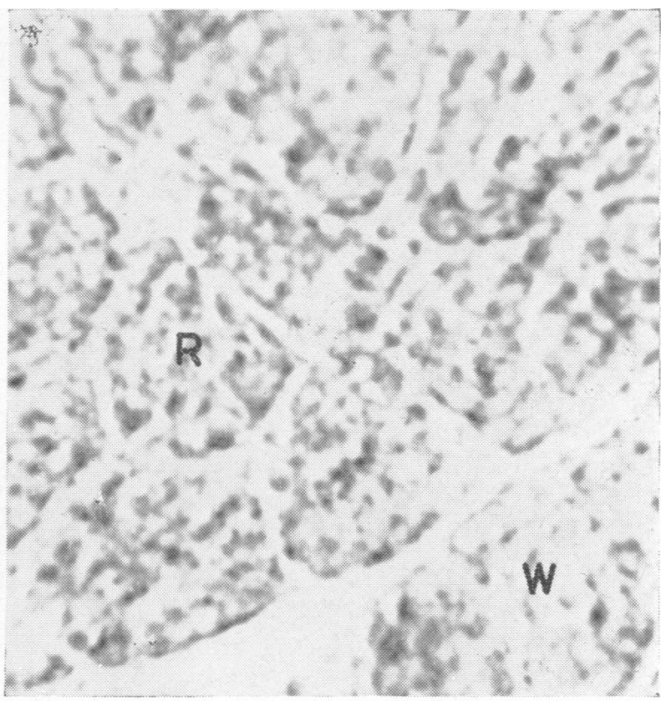

FIG. 14

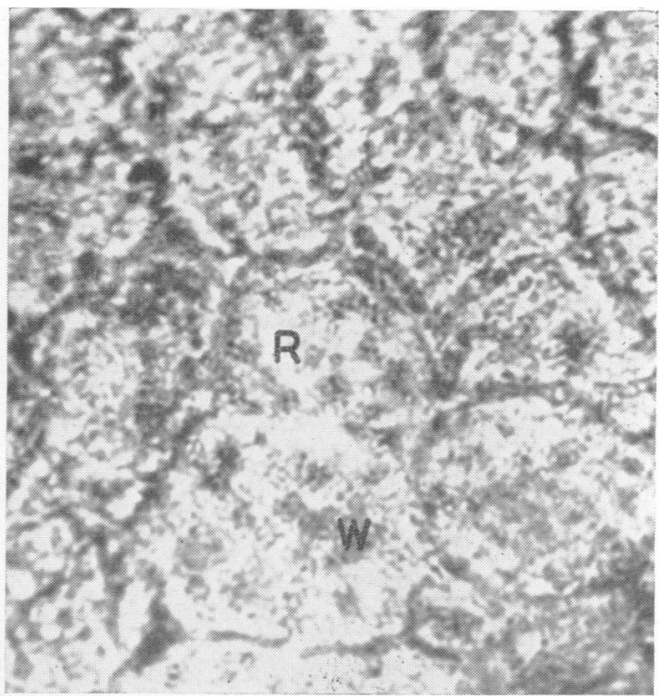

FIG. 16

FIG. 13. Photomicrograph of a transverse section of pectoralis muscle 21 days after denervation demonstrating a considerable decrease in lipase activity. Incubation time, $24 \mathrm{hr} ., \times 1,010$.

FIG. 14. Photomicrograph of a transverse section of pectoralis muscle 21 days after denervation showing the low activity of Tween 20 esterase even after prolonged incubation $(24 \mathrm{hr}.) . \times 1,010$.

FIG. 15. Photomicrograph of a transverse section of pectoralis muscle 30 days after denervation showing acid phosphatase activity. Red fibres $(R)$, and blood capillaries show high enzyme activity. Note the cell fragments of the degenerated white fibre (indicated by arrow) and the other partially degenerated white fibre (DW). Connective tissue (C) shows a negative reaction. Incubation time, five hours, $\times 1,010$.

FIG. 16. Photomicrograph of a transverse section of pectoralis muscle 14 days after denervation showing the level of alkaline phosphatase activity. An overall diminution in enzyme activity is seen. The red fibres $(R)$, however, show a relatively higher level of enzyme activity than the white ones $(W)$. Incubation time, $26 \mathrm{hr} ., \times 1,010$. 


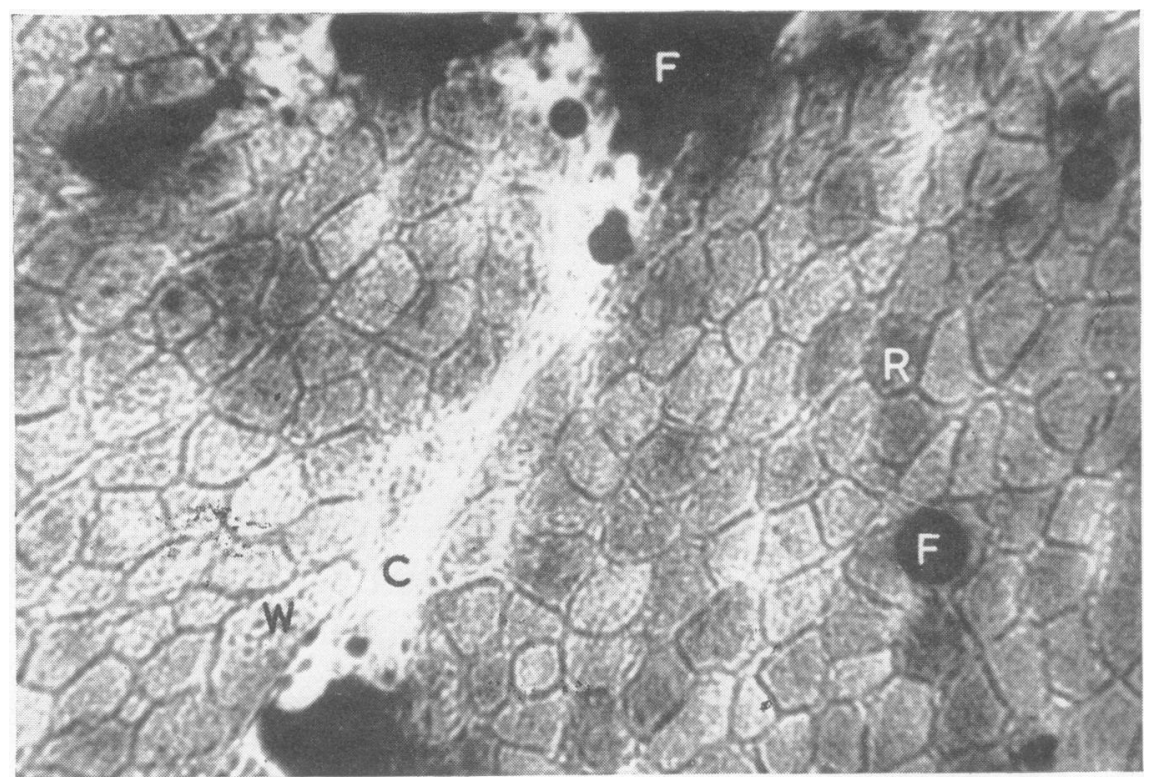

FIG. 17. Photomicrograph of a transverse section of pectoralis muscle 30 days after denervation showing the inter- and intra-fibrillar accumulation of fat $(F)$. Note that some of the red fibres are darkly stained for fat. $\times 400$.

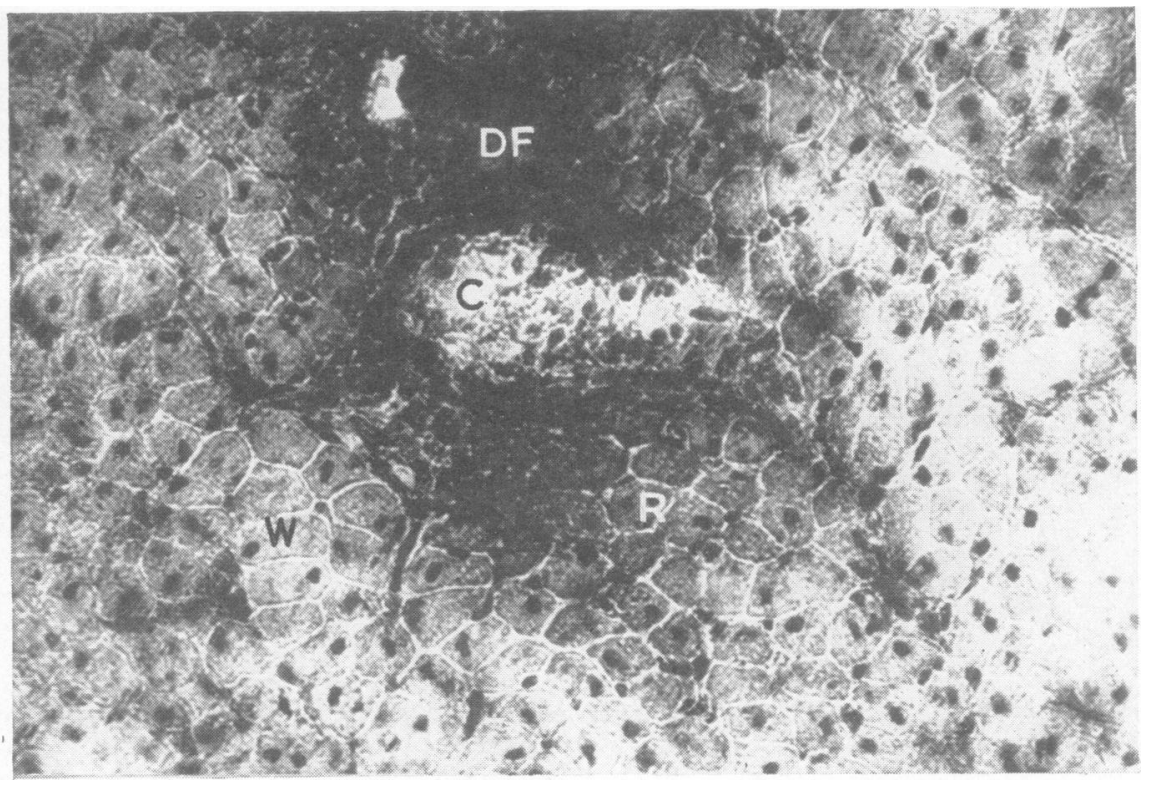

FG. 18. Photomicrograph of a transverse section of pectoralis muscle 21 days after denervation revealing the nature of specific sites of high acid phosphatase activity in the degenerating muscle fibres $(D F)$. Note the darkly stained fibres around the unstained space of connective tissue (C). Incubation time, five hours, $\times 400$. 
the present study. However, the changes observed in both types of fibre in denervated muscle were much sharper than in disuse atrophy. The white fibres did not regain their glycogen load and phosphorylase activity after $\mathbf{3 0}$ days, as in disuse atrophy. These differences may be ascribed to the slight muscular movements which were possible in the animals in plaster casts but not in the denervated animals.

During atrophy it is known that there is an accumulation of fat in the muscle (George and Vallyathan, 1962; Helander, 1960; Humoller, Hatch, and McIntyre, 1952), although it is not precisely understood how this fat accumulates. Perhaps it could be due to a diminished rate of utilization or a synthesis de novo by the muscle. Our recent investigations (Vallyathan et al., 1965) have given proof that during immobilization atrophy there is a lowered capacity for fatty acid oxidation with a possibility of fatty acids being synthesized in the muscle. From the present investigation it is seen that during atrophy, generally there is little fat in the muscle cells, as indicated by the weak staining. On the other hand, considerable accumulations of fat were seen in the interfascicular spaces of the muscle. A few red fibres, however, were seen to be loaded with fat. The activity of the pentose cycle dehydrogenases was found to be considerably increased during atrophy. Since the sections used in these observations were serial sections it was clear that the red fibres showing a high fat content also possessed high concentrations of the pentose cycle dehydrogenases. That the NADPH required for synthesis of fatty acids is supplied through the oxidative pathway of the pentose cycle is well known (Siperstein, 1958). Evidence provided by the studies of Rossi, Zatti, and Greenbaum (1963) and Zatti, Rossi, and Tartarini (1962) in the denervated rat muscle and of Fennell and West (1963) and McCaman (1963) in mouse dystrophic muscle indicate that there is a marked increase in the activity of the pentose cycle dehydrogenases. It may therefore be inferred that in atrophic muscle there is an increased synthesis of fat, and this fat, which is not utilized by the muscle (Vallyathan et al., 1965), accumulates in the muscle cells as well as in the intercellular spaces. There is a possibility that this fat finds its way out of the muscle cell, since it is known that in muscular atrophy the permeability of the cell membrane to various substances is increased.

In the present and earlier studies from our laboratories (Cherian et al., 1965) a decrease in the activity of SDH during atrophy was observed in the red fatmetabolizing fibres. The lowered level of this enzyme, which has a cardinal role in oxidative metabolism, is indicative of an impaired oxidative metabolism during atrophy. However, it was noticed that $\beta$ hydroxybutyric dehydrogenase activity of the denervated muscle was strikingly enhanced. This finding is consonant with the histochemical observations of Sibrik and O'Doherty (1963) on the dystrophic mouse muscle. The increase in $\beta$-hydroxybutyric dehydrogenase could not be attributed to an increased fat metabolism, as suggested by these authors, since in our present investigation there was a very low activity of succinic dehydrogenase. It is quite likely that this increase in $\beta$-hydroxybutyric dehydrogenase is due to an increased lipogenesis, since it is known that the enzymes taking part in the oxidation of fatty acids can also catalyse the reversible reactions leading to the synthesis of fatty acids. Moreover, our early studies also showed that fatty acids are not oxidized in vitro by atrophied muscle homogenate (Vallyathan et al., 1965). Nevertheless, the possibility of oxidation of fatty acids in vivo in at least some of the fibres cannot be ruled out entirely since an increase in the concentrations of both the above enzymes was observed in a few of the red and white fibres.

The results obtained for lipase activity reveal considerable decrease of this enzyme during atrophy. At the same time an increase in the Tween 20 esterase was observed in the early days of atrophy. George and Vallyathan (1962), using biochemical analysis, reported anincreased activity of the enzyme lipase in atrophied pigeon breast muscle using tributyrin as the substrate. This discrepancy between the biochemical data and the present histochemical findings may well be due to the substrate specificity of 'true' lipase. It was reported by George and Ambadkar (1963) and Bokdawala and George (1964) that Tween 85 is a specific substrate for true lipase. Recently, Bokdawala and George (1964), using Tween 85, demonstrated histochemically that lipase is localized in the mitochondria. In biochemical analysis, the substrate tributyrin, which is a triglyceride of short-chain fatty acid, is acted upon by both, by true lipase as well as by non-specific esterases. Our results for esterase activity are in good agreement with those of Fennell and West (1963) who obtained a similar increase in enzyme activity in mouse dystrophic muscle.

In human muscular dystrophy, Bourne and Golarz (1959) observed increasing concentrations of phosphatase activity in the connective tissue. Fennell and West (1963) and Romanul and Hogan (1965) obtained a strong reaction for acid phosphatase in the atrophied fibres and in the interfibrillar connective tissues. Intensive acid phosphatase reaction sites, which were restricted to specific areas in some fasciculi with both types of fibres, are seen to undergo atrophy. However, the individual white 
fibres undergoing degeneration did not show an increase of this enzyme. It may be stated that the increased activity of acid phosphatase during the earlier periods of atrophy may be in accordance with the increased rate of the catabolic activity in degenerating muscle. As regards alkaline phosphatase, Beckett and Bourne (1957) showed that in human dystrophic muscle there is an increase in the enzyme in some atrophied fibres and in the connective tissue surrounding them. A positive reaction for this enzyme was also reported by Smith (1965) in a few muscle fibres of the denervated rat tibialis. In the present study, however, enzymatic activity in the atrophied fibres as well as in the connective tissues surrounding them was found to be low.

Our findings have shown that some of the hydrolytic enzymes and the NADP-linked dehydrogenases are active in connective tissue. Bourne and Golarz (1959) suggested that the fundamental defect in progressive muscular dystrophy might be due to the increase in concentrations of these enzymes in the connective tissue. They gave three possible interpretations of their results, of which one seems to be most plausible. They suggested that the fundamental defect might be in the membrane of the muscle fibre and the diffusion of substrates out into the surrounding milieu might result in the adaptive synthesis of enzymes to hydrolyse them in the connective tissue (Golarz and Bourne, 1963).

From the present study it is evident that as a result of denervation there is a drastic change in the intracellular metabolism of the two types of muscle fibre. It was noticed that the majority of the red fibres are adapted to a glycolytic metabolism and the muscle as a whole to increased fat synthesis. Our findings are in agreement with the results of Bass and Hudlická (1961) who reported that during denervation atrophy there is a high rate of glucose and oxygen consumption, indicating an increase in the liberation of chemical energy. They have further suggested that this energy is used either for lipid synthesis or for the synthesis of other compounds, since the mechanism for utilization of chemical energy is impaired.

In our earlier experiments on atrophy in the pigeon induced by plaster casts (Cherian et al., 1965; Vallyathan et al., 1964) it was reported that the white fibres undergo structural changes and degenerate more rapidly than the red ones. In the present investigation these observations have been confirmed. Furthermore, it is found that with complete inactivation of the muscle, the red fibres also undergo rapid atrophy but with one major difference. At the onset of atrophy itself there is structural breakdown accompanied by biochemical changes in the white fibres whereas in the red fibres the changes taking place are chiefly biochemical and structural integrity becomes lost towards the final stages of atrophy. These biochemical changes are now shown to be brought about by a shift in metabolism from aerobic to anaerobic in the red fibres and vice versa in the white ones. Such a metabolic shift with the high rate of catabolism could be regarded as a factor promoting their degeneration.

\section{SUMMARY}

The histochemical changes in the red and white muscle fibres of the pectoralis muscle of the pigeon after complete inactivation of the muscle by denervation have been studied with respect to the localization of glycogen, fat, phosphorylase, succinic dehydrogenase, pentose cycle dehydrogenases, $\beta$ hydroxybutyric dehydrogenase, lipase, Tween 20 esterase, and acid and alkaline phosphatases. It was observed that the majority of the red fibres which are normally adapted to an aerobic metabolism changed to one of glycolytic metabolism, whereas the glycolytic white fibres shifted to an aerobic metabolism. The accumulation of lipid in the intercellular spaces and the higher activity of the pentose cycle enzymes indicated increased lipid synthesis? The significance of these observations is discussed.

\section{REFERENCES}

Bass, A., and Hudlická, O. (1961). Metabolism of the denervated muscle. V. Reaction and adaptation to load. Proc. 5th nat Congr. Czechoslovak physiol. Soc., 242-250.

Beckett, E. B., and Bourne, G. H. (1957). Some histochemical observa tions on human dystrophic muscle. Science, 126, 357-358.

Bokdawala, F. D., and George, J. C. (1964). Histochemical demonstration of muscle lipase. J. Histochem. Cytochem., 12, 768-771.

Bourne, G. H., and Golarz, M. N. (1959). Human muscular dystrophy as an aberration of the connective tissue. Nature, (Lond.) 183 1741-1743.

Cherian, K. M., Vallyathan, N. V., and George, J. C. (1965). Succinic dehydrogenase in the pigeon pectoralis during disuse atrophy. J. Histochem. Cytochem., 13, 265-269.

Eränkö, O., and Palkama, A. (1961). Improved localization of phosphorylase by the use of polyvinyl pyrrolidone and high substrate concentration. Ibid., 9, 585.

Fennell, R. A., and West, W. T. (1963). Oxidative and hydrolytic enzymes of homozygous dystrophic and heterozygous muscle of the house mouse. Ibid., 11, 374-382.

George, J. C., and Ambadkar, P. M. (1963). Histochemical demonstration of lipids and lipase activity in rat testis. Ibid., 11, 420-425.

$\longrightarrow$, and Naik, R. M. (1959). Studies on the structure and physiology of the flight muscles of birds. 7. The structure of the pectoralis major muscle of the pigeon in disuse atrophy. J. Anim. Morphol. Physiol., 6, 95-102.

succinic dehydrogenase and cytochrome oxidase activity in pigeon breast-muscle. Quart. J. micr. Sci., 102, 131-141.

$-1, \frac{1}{1962 a)}$. Histochemical demonstration of certain DPNlinked dehydrogenases and of aldolase in the red and white fibres of pigeon breast-muscle. Ibid., 103, 41-46.

,$--(1962 \mathrm{~b})$. Lipase activity of the particulate fractions of the pigeon breast muscle and its significance in the metabolism of the muscle. J. cell. comp. Physiol., 60, 33-39.

- and Vallyathan, N. V. (1962). Effect of disuse atrophy on pectoralis muscle and blood in the pigeon. Amer. J. Physiol., 202, 268-272. 
Golarz, M. N. and Bourne, G. H. (1963). In Muscular Dystrophy in Man and Animals. Edited by Bourne, G. H., and Golarz, M. N., p. 121. Karger, Basel.

Gomori, G. (1952). Microscopic Histochemistry, Principles and practice. University of Chicago Press.

Helander, E. (1960). Muscular atrophy and lipomorphosis induced by immobilizing plaster casts. Acta morph. neerl.-scand., 3 92-98.

Humoller, F. L., Hatch, D., and McIntyre, A. R. (1952). Effect of neurotomy on lipid content of striated muscle. Amer. J. Physiol., 169, 654-658.

McCaman, M. W. (1963). Enzyme studies of skeletal muscle in mice with hereditary muscular dystrophy. Amer. J. Physiol., 205, 897-901.

Pearse, A. G. E. (1960). Histochemistry-Theoretical and Applied, 2nd ed. Churchill, London.

Romanul, F. C. A., and Hogan, E. L. (1965). Enzymatic changes in denervated muscle. 1. Histochemical studies. Arch. Neurol. (Chic.), 13, 263-273.
Rossi, F., Zatti, M., and Greenbaum, A. L. (1963). Evidence for the existence of the hexose monophosphate pathway for glucose metabolism in the normal and denervated skeletal muscle of rats. Biochem, $J$. 87, 43-48.

Siperstein, M. D. (1958). Glycolytic pathways: their relation to the synthesis of cholesterol and fatty acids. Diabetes, 7, 181-188.

Smith, B. (1965). Changes in the enzyme histochemistry of skeletal muscle during experimental denervation and reinnervation. J. Neurol. Neurosurg. Psychiat., 28, 99-103.

Sibrik, Ilona De, and O'Doherty, D. S. (1963). Oxidative enzymes in muscular dystrophy. Neurology (Minneap.), 13, 554-557.

Vallyathan, N. V., Cherian, K. M., and George, J. C. (1964). Histochemical and quantitative changes in glycogen and phosphorylase during disuse atrophy of the pigeon pectoralis. J. Histochem. Cytochem., 12, 721-728.

(1965). Effect of disuse atrophy on fat metabolism in the pigeon breast muscle. J. Anim. Morphol. Physiol., 12, 235-245.

Zatti, M., Rossi, F., and Tartarini, A. (1962). Increased G-6-P dehydrogenase activity in pathological regressive processes of skeletal muscle. Ital. J. Biochem., 11, 418-427. 